\title{
LA REVISTA SUR Y EL EXILIO LITERARIO ESPAÑOL*
}

Nora Pasternac**

La Guerra civil española es relativamente importante en la historia de Sur; sin llegar a convertirse en una militancia demasiado ferviente, suscitó artículos y menciones en la revista; muchos de sus colaboradores y miembros se comprometieron con acciones directas a favor de la causa republicana de manera bastante notoria. Aun así no fue una actitud común en la vida de los colaboradores de Sur, que sostuvieron con vehemencia la necesidad de mantenerse alejados de la política inmediata y partidaria, proyecto que trataron de llevar a la práctica sin conseguirlo totalmente siempre. ${ }^{1}$

Por otra parte, la defensa de la República estuvo estrechamente ligada en Sur a la reivindicación de los intelectuales católicos, a pesar de la caracterización de 'liberal' que siempre mereció la revista. ${ }^{2}$ Hoy, salvo los estudios muy especializados sobre la época, ${ }^{3}$ casi nadie recuerda

* Con ligeras diferencias, este trabajo fue presentado en el 3er. Congreso Internacional del GEXEL, "Escritores, Editoriales y Revistas del Exilio Republicano de 1939", Barcelona, 17-21 de noviembre de 2003.

** Centro de Lenguas, ITAM.

${ }^{1}$ Esta breve introducción resume una infinidad de problemas y matices en los detalles que aparecen tratados en mi libro SUR: una revista en la tormenta. Los años de formación: 1931-1944, 2002, Buenos Aires, Paradiso. También desarrolla estas cuestiones el libro ya clásico de John King, SUR. Estudio de la revista argentina y de su papel en el desarrollo de una cultura, 1931-1970, 1989, México, FCE.

${ }^{2}$ Véase Nora Pasternac, "Las corrientes cristianas", op. cit., p. 89-109.

${ }^{3}$ Véase Cristián Buchrucker, Nacionalismo y peronismo. La Argentina en la crisis ideológica mundial (1927-1955), 1987, Buenos Aires, Sudamericana. 
cómo se establecieron las posiciones y el papel fundamental que desempeñó la revista Sur para nuclear a un cierto público católico junto a sus representantes y apartarlos de la extrema derecha, cuyos órganos de expresión se inclinaban por el franquismo en lo concerniente al conflicto español. Para ello, lo más relevante fue la 'apropiación' que la revista realizó de la figura, los artículos y los libros de Jacques Maritain. ${ }^{4}$ Junto a muchos otros escritores católicos opuestos a la idea del franquismo como espada flamígera de una guerra santa contra el comunismo, Maritain le ofrece las bases a la revista Sur para justificar una 'tercera posición' equidistante entre la derecha y ante todo alejada del campo de la izquierda-posiciones ambas sinónimo de la política 'politiquera' y coyuntural a la que siempre se negó-para defender la posición republicana.

Esta especie de lucha a favor del campo de la República española con el apoyo de las corrientes cristianas europeas se da en el interior de un país en el que el catolicismo 'oficial' seguía siendo mayoritariamente antirrepublicano y ligado a corrientes corporativistas y autoritarias. En la época en que Sur publica estos textos y realiza estas tomas de posición (me estoy limitando sólo a los años de la Guerra civil y a los primeros años de la década del cuarenta), sólo puede dirigirse a una minoría católica ilustrada e intelectual y propone las opciones del catolicismo social ante la contienda civil de la península. En eso consiste el tipo de intervención política que la revista elige. De todos modos, la guerra que se declara en Europa poco tiempo después de la derrota republicana y del comienzo del largo exilio español, borra toda referencia a la guerra española en beneficio de un amplísimo tratamiento de la guerra europea. A su vez, ambos acontecimientos aparecen estrecha-

${ }^{4}$ Sobre Maritain se puede consultar Brooke W. Smith, J.M.: Antimodern or ultramodern? An historical analysis of his critics, his thought and his life, 1975, Indiana, University of Notre Dame. De origen protestante, Jacques Maritain (1882-1960) se convirtió al catolicismo en 1906, siguiendo así una corriente que incluyó a muchos escritores que se convirtieron o volvieron al fervor católico, como, por ejemplo, Léon Bloy, Charles Péguy, Paul Claudel, Max Jacob, Jacques Rivière. Maritain es uno de los mentores del grupo católico que fundará la revista francesa Esprit en 1931 y con la que Sur comparte ciertos autores y referencias. 
mente ligados puesto que las preferencias 'franquistas' o 'republicanas' se transformarán en 'germanófilas' o 'aliadófilas' respectivamente.

En resumen, éste es el papel de la revista Sur que, a pesar de su moderación en lo que respecta a las polarizaciones relacionadas con el conflicto español, desempeñó una función bastante importante en las luchas culturales a partir del conflicto. Hay que examinar cuáles fueron las consecuencias del exilio de los intelectuales de la península hacia la Argentina en su relación directa con la revista.

Este exilio de intelectuales, poetas, pintores, músicos y tantos otros representantes de distintas artes, oficios y profesiones fue muy importante en número, y fundamental para la evolución de la cultura en el país, pero es menos recordada y homenajeada que, por ejemplo, en México. ${ }^{5}$ Una de las razones fundamentales de las diferencias está en la posición de los gobiernos ante la Guerra civil. El caso de México, con su posición oficial a favor de la República y el apoyo a la instalación de los exiliados no tiene parangón ni en América Latina ni en el mundo. Eso a su vez, dio una caución especial a las tareas intelectuales y un prestigio aureolado por la protección oficial. En Argentina, el gobierno no sólo no favoreció la llegada de los republicanos, sino que sus representantes se inclinaron más bien por el triunfo del franquismo sin grandes problemas de conciencia: no rompieron relaciones con los usurpadores y aceptaron inmediatamente la instalación oficial de la embajada del nuevo régimen. ${ }^{6}$

${ }^{5}$ Basta comparar la escasez de libros dedicados al tema en Argentina con las numerosas y detalladas historias, así como los libros, coloquios y artículos dedicados a la contribución de los exiliados españoles en México. En este caso, la bibliografía es inmensa; recordemos sólo dos que tienen la virtud de recoger una cantidad muy grande de casos: El exilio español en México. 1939-1982, 1982, México, Salvat-FCE; y Rose Corral, Arturo Souto Albarce y James Valender (eds.), Poesía y exilio. Los poetas del exilio español en México, 1995, México, El Colegio de México.

${ }^{6}$ Francisco Ayala recuerda: "[L]as autoridades argentinas, por contraste con las de México, Santo Domingo o Chile, no parecían demasiado propicias a dar la bienvenida a los republicanos huidos de Franco. Al entonces presidente Ortiz, cuya familia se preciaba de tener origen vasco, se le movió por fin el alma al dictar un decreto que, con carácter excepcional, permitía la admisión de los vascos; pero los demás españoles a quienes tal privilegio no se nos otorgaba, tuvimos que arreglárnosla cada cual como mejor pudo", "Mi Buenos 
Había en Buenos Aires varios españoles notables, colaboradores de Sur que ya residían allí desde antes de la Guerra civil, contratados por las universidades o por instituciones culturales en un proceso normal de intercambio, pero que no pudieron volver a España por ser republicanos y deben ser considerados exiliados como ellos mismos se declararon; luego están los exiliados propiamente dichos, si puede decirse así, que llegan a Buenos Aires escapando de la revancha de los vencedores y de los peligros que implicaría quedarse en España. Algunos pasan poco tiempo en el país y otros, como Rafael Alberti, se quedarán largos años. Hay varios colaboradores exiliados en otros países que escriben en Sur invitados por sus compatriotas y sabiendo que lo hacen en una revista que recoge el aporte de los republicanos. Finalmente, están los casos insólitos o especiales, de los cuales uno es el de Marañón, que formaría parte del territorio polémico explícito. Por otro lado, están los casos de Ortega y Gasset, Ramón Gómez de la Serna y María de Maeztu (parte de un conflicto subterráneo que sólo aparece indirectamente en la revista), que habrá que separar de la situación de los exiliados que no renunciaron a sus posiciones antifranquistas ni pudieron regresar a España.

Por las circunstancias de la Guerra civil, la revista se vio entonces enriquecida con excepcionales colaboraciones que tal vez no hubiera buscado activamente, pues nunca se caracterizó por un 'hispanismo' excesivo. $^{7}$

Aires querido", Recuerdos y olvidos 1. Del paraíso al destierro 2. El exilio 3. Retornos, 1988, Madrid, Alianza, p. 260.

${ }^{7}$ Por un lado, Victoria Ocampo descubrió tardíamente las virtudes de su lengua materna-escribía sus textos en francés-; por el otro, el hispanismo era una de las posiciones militantes -especialmente retrógrada en sus formulaciones- de la extrema derecha que, además, iba a apoyar al franquismo y perdurar en las formulaciones de la herencia española conservadora y católica. Véase el cap. 5 del libro de Emilia de Zuleta, Relaciones literarias entre España y la Argentina, 1983, Madrid, Ediciones Cultura Hispánica del Instituto de Cooperación Iberoamericana, p. 147-56. El capítulo "Catolicismo e hispanidad", de Marysa Navarro Gerassi (Los nacionalistas, 1969, Buenos Aires, Jorge Álvarez) explica claramente por qué revistas como Sur no podían ser muy afectas a los autores españoles y cómo el tema estaba acaparado por las revistas Criterio, Sol y Luna y otras de la orientación que señala el título del capítulo. 
Casi todos los poetas españoles conocidos publican durante esa época de Sur que coincide con la Guerra civil y el comienzo de la Segunda guerra mundial. La extensión de esta ponencia no me permite más que una escueta lista sin análisis. El primero de ellos por la cantidad de poemas que publica es Rafael Alberti, ${ }^{8}$ acompañado por Federico García Lorca, Jorge Guillén, Salvador de Madariaga, Rosa Chacel, Juan Gil-Albert, Juan Ramón Jiménez, José Moreno Villa, Manuel Altolaguirre, Enrique Díez Canedo, Pedro Salinas, Arturo Serrano Plaja, y muchos más durante el resto de la década de 1940 y siguientes. Todo ello va sostenido por las abundantísimas reseñas y artículos sobre los libros publicados por estos poetas, lo cual aumenta su presencia en las páginas de la revista. Eduardo González Lanuza, español de origen, pues nació en Santander, aunque había llegado a la Argentina a los nueve años de edad, en 1909, es uno de los más fervientes interesados en la literatura española moderna en Sur y se encarga de darnos una especie de síntesis:

En todos los poetas de lo que con justicia se ha llamado 'la España peregrina' subsiste el tono elegíaco y la añoranza dentro de los matices que van desde la imprecación hasta la melancolía. Pero en algunos [...] eso no impide que el fuego mediterráneo que alienta en sus entrañas irrumpa de pronto, jocundo y colorido. En cambio [en otros] se advierte una especie de sorda complacencia, como en la de los místicos al

${ }^{8}$ Curiosamente, a comienzos de la década del noventa, en declaraciones a un diario mexicano, Alberti rememora con cierto resentimiento su relación con Sur: "Al recordar anécdotas de sus 23 años de exilio en Argentina, el poeta español [...] dijo que no tuvo relación alguna con el escritor Jorge Luis Borges 'porque él tenía sus ideas personales y no era amigo de mucha gente, era inabordable' [...] Alberti agradeció a José Bianco, el fallecido novelista y secretario de la desaparecida revista literaria Sur, por haber publicado sus notas 'de vez en cuando y una obra de teatro en tres entregas'. Alberti afirmó que 'tenía diferencias políticas con la directora de Sur, Victoria Ocampo [...] quien en realidad nos despreciaba", Unomásuno, 27 de abril de 1991, México, p. 28. Se trata de un recuerdo extrañamente deformado, pues Alberti publicó en la revista poemas y relatos además de la obra de teatro y las notas que menciona, y mereció artículos y reseñas sobre los libros de poemas que publicó durante su estancia en el país. Por otra parte, estas colaboraciones de los exiliados eran pagadas, y generosamente, por la revista o por su directora, cuando los fondos oficiales escaseaban. 
comprobar la inanidad de las cosas terrenas, pero que al revés de éstos, no coloca su confianza en la luminosidad de un más allá sino que hace de esa luminosidad rigor de tiniebla porque la torna perceptible. ${ }^{9}$

Un grupo de narradores, algo menor que el de los poetas, también publica sus relatos en Sur, y a pesar de que también se trata de exiliados, presenta algunas discordancias con respecto al sentido del exilio. El principal colaborador de esos años -numéricamente hablando- es Ramón Gómez de la Serna; luego vienen Rosa Chacel, Benjamín Jarnés, Francisco Ayala, José Moreno Villa, Rafael Alberti y, en una de sus raras intervenciones directas en la revista, José Ortega y Gasset, que publica una versión propia de un cuento de Sudán sacado de una transcripción realizada por Leo Frobenius en su libro Und Africa sprach (1912).

A diferencia de los poetas que trajo el exilio, no todos los colaboradores de prosa narrativa siguieron siendo republicanos. El acto más determinante de Ortega es la decisión expresa de solicitar que se elimine su nombre del Comité de Redacción. ${ }^{10}$ Había llegado a Buenos Aires por tercera vez en 1939 desde Francia en donde se había instalado al comenzar la guerra de España y abandona a causa del comienzo de la Segunda guerra mundial. Pasa cerca de tres años en Buenos Aires, antes de instalarse en Portugal y de volver definitivamente a España. Sus anteriores viajes a la Argentina (1916 y 1928) estuvieron marcados por éxitos fulgurantes y brillantes presentaciones que le ganaron seguidores fervientes. Esta última visita a Buenos Aires se desarrolla en medio de la polarización que produjo la Guerra civil y está signada por el conflicto con sus antiguos seguidores e incluso con la revista de Victoria Ocampo. Por otra parte, en esa última estadía se acercó a los

${ }^{9}$ Eduardo González Lanuza, “Arturo Serrano Plaja: Versos de guerra y paz, 1945, Buenos Aires, Nova, Sur, 132, octubre de 1945, p. 110.

${ }^{10}$ Un poco después de que también Drieu la Rochelle tomara la misma decisión; ambos lo hicieron por la toma de posición de la revista en favor de los republicanos. Drieu la Rochelle ya estaba en las filas del fascismo francés para luego iniciar un recorrido que lo llevaría a la colaboración con los nazis y al suicidio cuando los alemanes fueron derrotados. 
jóvenes nacionalistas de la revista de extrema derecha y partidaria del franquismo, Sol y Luna, que estaba bajo la conducción del llamado 'nacionalismo doctrinario', como la caracteriza Emilia de Zuleta. ${ }^{11}$ En realidad, la gran figura que aparece en Argentina recomendada por Ortega, y que se convierte en uno de los colaboradores más frecuentes de Sur en su primera época, es Ramón Gómez de la Serna. Es el otro caso de narrador que no dio su adhesión a la República. Más bien lo contrario. Aunque se presenta a sí mismo como un 'mediador' y como una víctima de la guerra por no estar con ninguno de los dos campos, termina colaborando con los diarios franquistas desde el comienzo de

${ }^{11}$ Op. cit, p. 147. Uno de los fenómenos más curiosos es justamente esta relación que se mantiene en la revista con Ortega. En vida, sólo se publicaron dos textos de él, de una importancia menor para su pensamiento: el cuento que acabo de mencionar, 'Dan Auta', en el número 25, y un artículo sobre la piratería de las editoriales chilenas que provocó la ira de Neruda así como una agria polémica del poeta con la revista, 'Ictiosaurios y editores clandestinos', en el número 38. Sin embargo, se vincula muy fuertemente a Sur con el polígrafo español. En realidad, la influencia de Ortega aparece de manera indirecta, a través de sus seguidores o admiradores, como una sombra y una referencia constante que se refleja en muchos colaboradores. Estos conflictos que acabo de describir apenas pueden ser reconstruidos hoy, pues nunca estallan con la fuerza que tuvo el de Gregorio Marañón, del que me ocuparé más adelante. Además, hay que decir que desde el primer número de la revista, Ortega y Gasset es colocado en lugar mítico, lo cual parecía excluir de antemano cualquier debilidad y la posibilidad de la crítica: "Entonces llamé por teléfono a Ortega, en España. Esas gentes tienen costumbre de bautizarnos... Así, Ortega no vaciló y, entre los nombres enumerados, sintió enseguida una preferencia: SUR me gritaba desde Madrid" (Victoria Ocampo, "Carta a Waldo Frank, Sur, 1, verano de 1931, p. 14). Y en el momento de su muerte, la revista le dedica un número especial, el 241, lleno de homenajes; por otra parte, Ortega está siempre presente en los autores de Sur, con reconocimiento intelectual y apreciación constante sin críticas. La excepción es Patricio Canto, colaborador asiduo de la revista, sobre todo durante la década del 40 y parte del 50, que escribe un violento texto contra el filósofo, denunciando sus incongruencias políticas y analizando las debilidades de su pensamiento: El caso Ortega y Gasset, 1958, Buenos Aires, Leviatán. Representa todo un síntoma de decepción de los jóvenes con respecto al filósofo español. Para colmo: "Los hijos de Ortega se enrolarán inmediata y voluntariamente en el ejército de Franco. Igual que habían hecho o harán los de Gregorio Marañón, Ramón Pérez de Ayala y Eugenio d'Ors. Sus padres seguirán puntualmente el desarrollo bélico a partir del compromiso de sus hijos" (Gregorio Morán, El maestro en el erial. Ortega y Gasset y la cultura de lo franquismo, 1998, Barcelona, Tusquets, p. 57). Hay que decir que, a pesar de la relación tormentosa que Victoria Ocampo tuvo con él en el plano personal, ella nunca dejó de ayudarlo y sostenerlo, aunque no se pudieron evitar ciertas decepciones y distanciamientos. 
la década de los cuarenta y aun antes. ${ }^{12}$ Además, se ve envuelto en una circunstancia agravante para los escritores que rodean a la revista Sur: se acerca a los círculos peronistas con los que mantiene relaciones. Sus colaboraciones son muy abundantes en Sur, pero cesan bruscamente a partir de 1940; tanto Gómez de la Serna como Ortega desaparecen de la revista para reaparecer mucho más tarde bajo la forma de homenajes y completamente purificados por el tiempo y la distancia; no obstante, no se encuentra ninguna mención de las razones de esa desaparición en los textos de la publicación ni ninguna explicación de su ausencia. Curiosamente, este silencio es una consecuencia de la convicción orteguiana que Victoria Ocampo tenía de las relaciones de los intelectuales con la política. ${ }^{13}$ Porque, por otra parte, 'Ramón', como aún le dicen sus admiradores, era uno de los modelos más acabados de cierta actitud festival, aristocratizante y ligera de la literatura, tal como la hubiera querido José Ortega y Gasset.

Durante el curso del año 1937 se produce uno de los más ásperos conflictos de esa época en el interior de Sur: aparece un artículo de Gregorio Marañón, quien un poco antes había salido de España, reti-

${ }^{12}$ Véase Ramón Gómez de la Serna, “Aires de fronda. La revolución. Quince días de oír las ametralladoras y viaje a la Argentina", "Lucha por la existencia. Peligro de los conciliadores", Automoribundia (1888-1948), 1948, Buenos Aires, Sudamericana, p. 609-12 y p. 627-30. Llega a la Argentina precedido por una gran popularidad y la veneración que le tenían los martinfierristas ya reagrupados, en su mayoría, en la revista de Victoria Ocampo. Retorna a España, pero a partir de 1937 vuelve para instalarse definitivamente en Buenos Aires. Comienza a colaborar semanalmente en el diario español Arriba así como en el porteño El Mundo y prosigue escribiendo libros y artículos en Buenos Aires.

${ }^{13}$ En una de las numerosas versiones que expuso de esta idea, escribe: "En las primeras páginas de Revista de Occidente ('Propósitos'), Ortega [...] declara en julio de 1923 que la revista dará la espalda a la política, porque la política 'no aspira a entender las cosas'. Por desgracia, la política, que no aspira a entender las cosas, iba a apoderarse del mundo, a convertirse en casi el único tema de nuestro tiempo", dice llena de pesar justamente en "Homenaje a Ortega" (Sur, 241, julio-agosto de 1956, p. 207). A despecho de su desdén por la política y el que tratara de mantenerla alejada de su revista a imitación de la de Ortega, recuerda más tarde: "La política, que jamás jugó el menor papel en mi existencia, [...] ha causado cantidad de derrumbes en mi vida amistosa. María [de Maeztu] (como Ortega, Drieu y ahora María Rosa [Oliver] fue uno de esos derrumbes", Autobiografía IV. Viraje, 1982, Buenos Aires, Sur, p. 117. 
rándose en plena Guerra civil hacia América del Sur. Este artículo, ${ }^{14}$ aunque no alude al enfrentamiento, motiva una carta de José Bergamín, director de la revista Cruz y Raya, y a quien Victoria Ocampo solicitó más de una vez consejo para la publicación de artículos. La carta de Bergamín comienza en estos términos: "Me llega aquí, y ahora, la noticia de la hospitalidad por usted ofrecida en Buenos Aires al desbaratado doctor Marañón, el más que médico o curandero de su deshonra, traficante de ella." ${ }^{15}$ Marañón se había alejado de España a pesar de que un tiempo antes había declarado: "Mi deber de español es quedarme en España." Y Bergamín, que participaba directamente en la defensa de Madrid, le reprocha violentamente haber abandonado la lucha. La discusión es sumamente agria aunque Victoria Ocampo, de acuerdo con la tendencia dominante de la revista en esos años, en consonancia con la influencia que en ese sentido había ejercido sobre Sur la revista Cruz y Raya, apela al catolicismo de su acusador: "Me habían hablado de usted como un grande y auténtico católico [...] vale decir que me habían hablado de usted como de un verdadero cristiano (ése es el término que me conmueve)."16

${ }^{14}$ Gregorio Marañón, "Soledad y Libertad”, Sur, 31, abril de 1937, p. 60-91. La figura de Gregorio Marañón fue objeto de polémica desde los primeros años de la Guerra civil. Cosa que señalan Carlos Blanco Aguinaga, Julio Rodríguez Puértolas e Iris M. Zavala en Historia social de la literatura española (en lengua castellana), 1978, Madrid, Castalia, en su capítulo del tomo 3, "El siglo XX. La Guerra Civil". Van en el mismo sentido las valoraciones negativas de Marañón en la más reciente Historia crítica de la literatura española (1992, Barcelona, Crítica), dirigida por F. Rico. También en la poesía popular de carácter circunstancial, constituida por coplas elementales e imitaciones de los romances, que escribían los combatientes republicanos aparecen las alusiones a la defección de Marañón: por ejemplo, Félix Paredes le dirige su libro de versos satíricos, Profesor de traiciones. Véase también ULTRAMAR. Revista mensual de cultura, ed. facs. con estudio introductorio de James Valender, 1993, México, El Colegio de México.

15 "Cartas abiertas: de José Bergamín a Victoria Ocampo-de Victoria Ocampo a José Bergamín”, Sur, 32, mayo de 1937, p. 67-74.

${ }^{16} \mathrm{Ibid}$, p. 70. De hecho, José Bergamín envió una disculpa inmediata a Victoria Ocampo, pero en ella incluía algunas otras consideraciones que hicieron que la polémica continuara en el número siguiente, pero ya a propósito del problema de la mujer y de su condición. 
Hay que recordar que María Zambrano, muy cercana a Sur y colaboradora frecuente en esos años, parece terciar en la disputa cuando publica en Chile un libro que se termina con una extensa carta a Marañón llena de graves reproches. Al mismo tiempo, ataca dura y largamente a los que pretendían aparecer como neutrales o 'mediadores' tanto como a los partidarios del arte puro:

Los que no supieron encontrar en sí mismos estas reservas de humanidad y se metieron en la cueva oscura de la impotencia disfrazada de arte o pensamiento más o menos puro, han quedado por debajo de los tiempos, incapaces de toda acción creadora. De entre ellos, los incapaces de correr el riesgo de ser hombres, han salido los neutrales y los renegados que aprovecharon el salir de las fronteras españolas para lanzar su resentimiento. ${ }^{17}$

Finalmente, hay que señalar la inmensa importancia de algunos de los investigadores, eruditos y ensayistas que la guerra trajo, tanto directamente como indirectamente, en cierto modo, cuando los estudiosos que ya estaban antes del estallido viviendo en la Argentina decidieron quedarse porque se sentían identificados con alguna fracción del campo republicano y estimaron que su vuelta a España era imposible.

Uno de los primeros casos que hay que mencionar es el de Guillermo de Torre (1900-71). Se vinculó con la vida intelectual argentina desde 1927 cuando empezó a residir en el país. Fue uno de los iniciadores del movimiento ultraísta en 1919, colaborador de la Revista de Occidente desde 1924 y secretario fundador de La Gaceta Literaria en 1927. Desde su llegada a Buenos Aires, publicó en diarios y revistas, se relacionó con Eduardo Mallea y Victoria Ocampo y siguió sus vínculos con Jorge Luis Borges, con cuya hermana, la pintora Norah Borges, se casó. En 1932, volvió a España donde trabajó con Pedro Salinas en los Archivos de Literatura Contemporánea del Centro de Estudios Históricos y en diversas revistas. Al estallar la Guerra Civil se instaló en

${ }^{17}$ María Zambrano, Los intelectuales en el drama de España, 1937, Santiago de Chile, Panorama, p. 39. 
Buenos Aires. Fue el primer secretario de la revista Sur y su influencia en ella resultó muy importante en varias cuestiones políticas y culturales. De hecho, su ascendiente en el campo cultural argentino es más profundo de lo que se recuerda actualmente: aparte de sus relaciones con escritores, pintores y artistas nacionales y extranjeros, siguió ligado a las revistas literarias y culturales, y fue asesor literario, primero de la editorial Espasa-Calpe, y luego cofundador y asesor de la editorial Losada. En Sur escribió abundantemente, muy a menudo sobre temas y autores españoles. Por otra parte, tiene una obra ensayística muy extensa de la cual la más recordada es Literaturas europeas de vanguardia (1925; edición corregida y ampliada en 1965).

Ricardo Baeza (1890-1956) también se instala en Buenos Aires a causa de la guerra. Una de sus contribuciones, entre tantas en la revista, fue la preparación del número especial de Sur consagrado a Cervantes, el 158 de diciembre de 1947. Asimismo fue traductor, para generaciones de estudiantes de filosofía argentinos, de Nietzsche. Tradujo al español a Wilde, a D'Annunzio y a muchos otros autores europeos. Dejó un abundante obra crítica recogida en varios volúmenes.

Una figura central entre los colaboradores españoles fue Francisco Ayala, que se exilió en Buenos Aires donde residió hasta 1950. Fue un colaborador asiduo de Sur con relatos, ensayos sociológicos, sobre la creación literaria, el cine, el problema de España, además de comentarios y reseñas. Su Tratado de sociología (1947) era un texto muy consultado por los estudiantes universitarios de los años cincuenta y sesenta, hasta que se van consolidando grandes cambios y variantes en los estudios sociológicos argentinos. ${ }^{18}$ Es uno de los autores que presta mayor atención al liberalismo; en cierto modo, la influencia que Ayala ejerció en los medios universitarios y su cercanía con la revista hicieron más fácil la percepción de Sur como revista identificada con las preocupaciones liberales.

${ }^{18}$ Sobre estas transformaciones y cuestionamientos a la tradición que Francisco Ayala representaba, véase Oscar Terán, Nuestros años sesentas. La formación de la nueva izquierda intelectual argentina. 1956-1966, 1993, Buenos Aires, Catálogo, 3a , El cielo por asalto; y Silvia Sigal, Intelectuales y poder en la década del sesenta, 1991, Buenos Aires, Puntosur. 
Rosa Chacel, María Zambrano, Salvador de Madariaga, Enrique Díez-Canedo, Federico de Onís y Américo Castro ${ }^{19}$ también colaboraron con ensayos, artículos y reseñas, aparte de que algunos ya aparecieron en el grupo de narradores y poetas que señalé más arriba; pero, para terminar esta exposición, hay que mencionar uno de los casos más importantes, tanto en lo que se refiere a su participación en la revista, como a su influencia en el campo de estudios que contribuyó a enriquecer. Se trata de Amado Alonso (1896-1952). Invitado por la Universidad Nacional de Buenos Aires, llegó en 1927 y se hizo cargo del Instituto de Filología, que dirigirá hasta 1946. Cuando se produce la derrota de la República española, se identifica con el exilio y decide quedarse definitivamente en la Argentina. En 1946, los conflictos con el peronismo, ya bien instalado en el poder, lo hacen abandonar el país y continuar su carrera en México y luego en Estados Unidos. La crítica argentina le debe sobre todo la introducción temprana de la estilística como método de análisis literario. Junto con Raimundo Lida, otro colaborador de la revista y de la editorial Sur, Amado Alonso creó la Colección de "Estudios estilísticos", publicada por el Instituto de Filología de la Facultad de Filosofía y Letras de la Universidad de Buenos Aires; en ella se tradujeron y editaron obras clásicas de la disciplina, como los libros de Karl Vossler, Charles Bally y otros autores fundamentales para la teoría estilística. ${ }^{20}$ En 1943, Amado Alonso traduce, presenta y anota el Curso de lingüística general de Saussure, y fija con esa traducción y su prólogo la terminología saussureana para todo el ámbito de la lengua hispánica ('significante', 'significado', 'signo', 'habla', etc.)

${ }^{19}$ A quien Borges le dedicó una indignada y mordaz crítica por su libro sobre el habla del Río de la Plata: Jorge Luis Borges, "Los libros. Américo Castro: La peculiaridad lingüística rioplatense y su sentido histórico (1941, Buenos Aires, Losada)" en Sur, 86, noviembre de 1941, p. 66-70. Esta reseña fue retomada como artículo en Otras inquisiciones (1952) con el título de "Las alarmas del doctor Castro". Véase también mi artículo "El anticervantismo de Borges: de Paul Groussac a Pierre Menard", Actas del XXIX Congreso del Instituto internacional de Literatura Iberoamericana, 15-9 de junio de 1992, Barcelona, Universitat de Barcelona, p. 953-65; Estudios, ITAM, Invierno 1992-3, p. 51-66.

${ }^{20}$ También fue fundador de la colección "Filosofía y teoría del lenguaje" en la editorial Losada. 
El establecimiento de la terminología hecho por Alonso contribuyó a dar homogeneidad y rigurosidad a los estudios lingüísticos en América Latina. Realizó valiosos análisis estilísticos de Don Segundo Sombra, de Jorge Luis Borges, del modernismo de Enrique Larreta y fue uno de los primeros estudiosos de Pablo Neruda. Además, escribió numerosos análisis de gramática, de fonología y de fonética histórica; fundó la "Biblioteca de Dialectología Hispanoamericana" junto con Ángel Rosemblat y Alberto Espinosa. Se ocupó particularmente de la realidad lingüística hispanoamericana (El problema de la lengua en América, 1953) y, junto con Pedro Henríquez Ureña, escribió la Gramática Castellana (1938), tantas veces reeditada, y que en su momento significó un avance extraordinario en la enseñanza del idioma en la Argentina. De toda esta actividad quedan amplias huellas en sus artículos en Sur.

Una gran cantidad de estudiosos - de los cuales una buena parte colaboró en Sur- se convirtieron en especialistas en las investigaciones lingüísticas y literarias a partir de su magisterio: Ángel J. Battistesa, Eleuterio Tiscornia, Raimundo Lida, Enrique Anderson Imbert, María Rosa Lida, Emilio Carilla, Raúl H. Castagnino, Antonio Pagés Larraya, Guillermo Ara, Augusto Cortázar y tantos otros. Claro que ese magisterio no se ejerció desde la revista sino de manera indirecta y se desarrolló sobre todo en los ámbitos universitarios y de la investigación institucional.

En resumen, al realizar el análisis de los efectos de la Guerra civil española ejercidos a través de la revista Sur sobre el entorno cultural, se desprenden claramente dos líneas. Por un lado, la influencia que la revista tuvo sobre la opinión católica a propósito del conflicto, y por otro, la inmensa riqueza que representó el aporte de los escritores, poetas, ensayistas y eruditos que la guerra arrojó fuera de su patria. En el caso de estos últimos, se produjo incluso un viraje en la investigación sobre los hechos literarios y lingüísticos con una influencia directa sobre la realidad de la enseñanza y su calidad, y al ofrecerles un lugar de difusión, Sur no fue totalmente ajena a esta transformación. 
La reproducción total o parcial de este artículo se podrá hacer si el ITAM otorga la autorización previamente por escrito. 